\title{
Retraction Note: The sequential magnetic resonance images of tri-methyl tin leukoencephalopathy
}

\author{
Chang Ho Hwang
}

Published online: 2 March 2012

(c) Springer-Verlag 2012

\section{Retraction note: Neurol Sci (2009) 30:153-158}

\section{DOI 10.1007/s10072-009-0028-8}

The article: "The sequential magnetic resonance images of tri-methyl tin leukoencephalopathy" (Hwang CH (2009) Neurol Sci 30(2):153-158) has been retracted upon request of the author since he unintentionally reported clinical data already published in the article "A case of acute organotin poisoning" (Yoo CI, Kim Y et al (2007) J Occup Health 49:305-310).

The online version of the original article can be found under doi:10.1007/s10072-009-0028-8.

\section{H. Hwang ( $\square)$}

Department of Physical Medicine and Rehabilitation,

Ulsan University Hospital,

University of Ulsan College of Medicine,

290-3 Jeonha-dong, Dong-gu, Ulsan 682-714, Korea

e-mail: chhwang1220ciba@yahoo.co.kr 